\title{
METHODS OF OR: A NEW GRADUATE COURSE
}

\author{
PduT FOURIE, I NIEUWOUDT \& JH VAN VUUREN \\ Department of Applied Mathematics \\ University of Stellenbosch \\ Private Bag X1, 7602 Matieland \\ Republic of South Africa
}

\begin{abstract}
A new course entitled "Methods of Operations Research (OR)" was introduced at the Department of Applied Mathematics of Stellenbosch University during the second half of 2001. The aim of this course was to introduce students of OR to the trauma of mathematical modelling in real-world scenarios, instead of merely teaching them a number of theoretical OR-related topics in the form of a lecture-driven course with an examination at the end. Therefore this project-driven course, which is offered in collaboration with a number of partners in industry, is assessed on a continued evaluation basis, by means of written reports and oral presentations by students, after having physically, or at least virtually, visited real-world OR application sites. The objectives of the course, its structure and contents, as well as lessons learnt and some student feedback are described in this paper. A selection of projects used in the course are described in some detail in an appendix.
\end{abstract}

Keywords: Practical OR Education; Training of OR Practitioners.

\section{INTRODUCTION}

In this paper the authors describe a new graduate course, entitled "Methods of Operations Research (OR)," which was introduced by them to the curriculum of the Department of Applied Mathematics at Stellenbosch University, South Africa in 2001. The department is part of the Faculty of Engineering, and courses are offered to science as well as engineering students. The focus areas in the department are: operations research, discrete mathematics, numerical analysis, and fluid dynamics. Although no explicit OR courses are offered by the department at undergraduate level, several relevant topics occur in regular applied mathematics courses at undergraduate level, such as probability theory, statistical analysis and classical optimisation theory. There is also a strong emphasis on 
modelling in all courses within the department, this being regarded as one of the distinguishing characteristics of applied mathematics compared to, say, pure mathematics or engineering mathematics. The department offers three graduate courses relevant to OR, namely graph \& network theory, mathematical programming and the new course described in this paper. These may form part of the standard honours programme in applied mathematics, or of an interdisciplinary honours programme in OR, offered collectively by the departments of mathematics, applied mathematics, statistics, computer science, industrial engineering and logistics, including courses on a wide range of OR topics, such as queueing theory, inventory control, supply chain management, computer simulation and stochastic modelling.

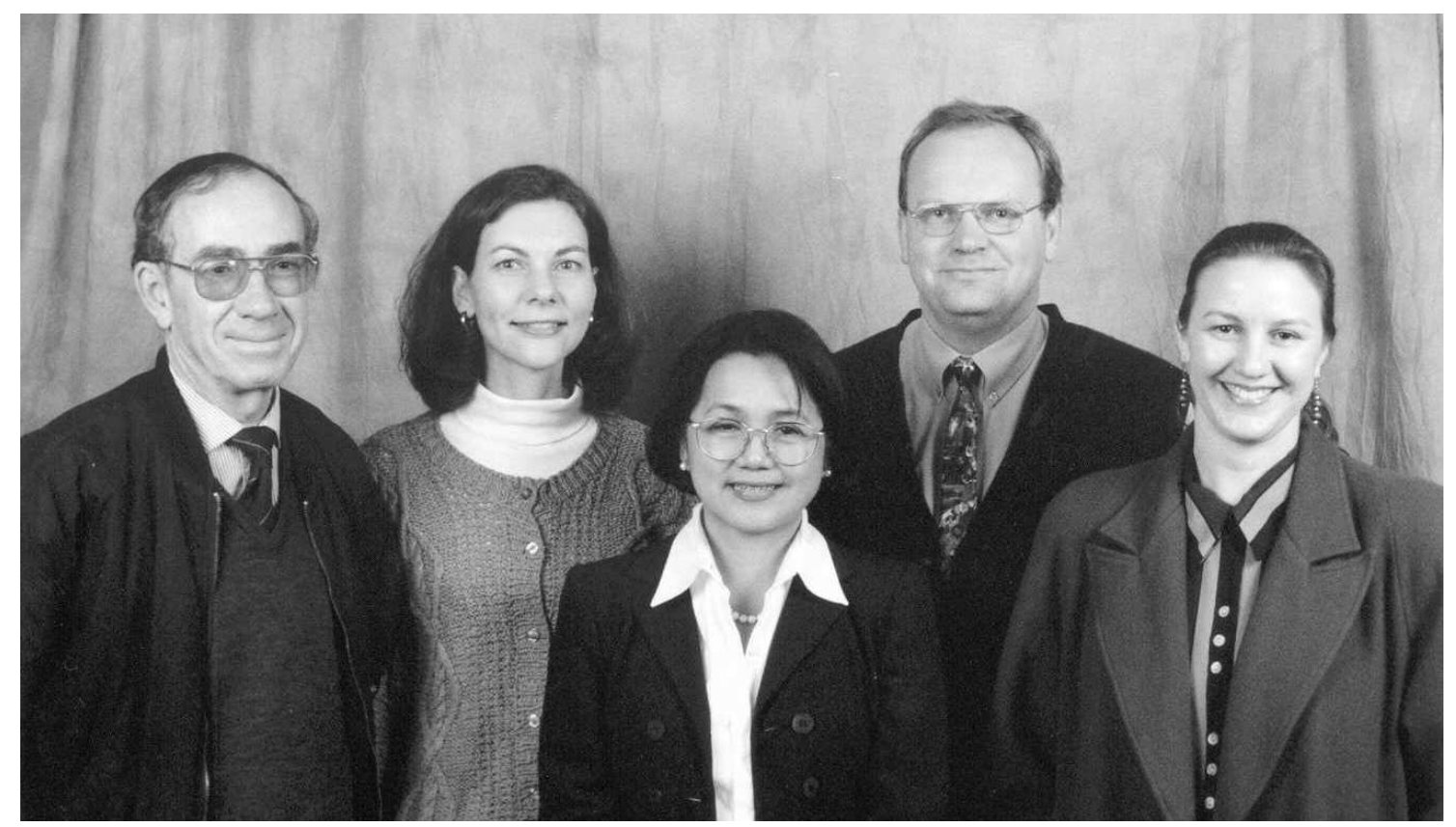

Figure 1: This picture shows Elise del Rosario (centre), who inspired the course described in this paper, together with the three authors, Philip Fourie (left), Jan van Vuuren (second from right) and Isabelle Nieuwoudt (right), and a colleague of theirs, Elmari Roos (second from left), who has subsequently left the Department of Applied Mathematics at Stellenbosch University.

During September 2000 a well-known member of the international OR community, Elise del Rosario, (then Vice-President of IFORS and chair of the Developing Countries Committee; see Figure 1) attended the annual conference of the South African OR Society, and also visited the Department of Applied Mathematics at Stellenbosch. She gave a talk on "OR at the San Miguel Corporation (SMC)," during which she described the role that OR played in all the activities of SMC, as well as the responsibilities of members of the OR department there, and the training given to new members. As a result of Elise 
del Rosario's visit, the authors realised that there was an element missing in the training of students in OR at Stellenbosch, namely the practical element of problem formulation at real-world OR application sites, as opposed to the study of mere solution techniques for already formulated problems. While students leaving the Department of Applied Mathematics at Stellenbosch were typically able to solve well-defined, already formulated and usually very neat textbook example problems presented to them, by means of a large number of sophisticated analytical and numerical techniques, the point was, in the words of Powell [7], that "the heart of Management Science [and indeed OR] itself is not the impressive array of tools that have been built up over the years (optimisation, simulation, decision analysis, queuing [theory], and so on) but rather the art of reasoning logically with formal models." Unfortunately, OR students leaving Stellenbosch were typically not being exposed to the rather traumatic experience of making sense of real-life problems during regular-style courses. These problems are often characterised by conflicting objectives, incomplete or inaccurate data sets, and even uncertainty on the part of the role-players as to what the problem or objective actually is. Furthermore, there is typically no preferred or suggested approach to solving such problems; it is up to the modeller to come up with an appropriate solution technique suited to the intricacies of the problem at hand, based on his/her practical experience.

The key word here is experience, but the young person starting out as an OR practitioner is confronted by the catch-22 situation that the main ingredient in the practice of good OR is experience, but that experience can only be acquired by the practice of OR. Hence it was decided that a course aimed at training young people to enter the world of OR practice could not be taught wholly in the form of regular-style theoretical lectures in which students are "taught" how to practice OR, nor could it be examined by means of regularstyle written examinations in which students are expected to reproduce samples of what they had learnt during the course. The point is that experience cannot be conveyed to students by (even the most experienced) lecturers during formal contact sessions; students must discover good and bad modelling techniques and solution approaches by themselves during practical projects, and can, at most, be guided by lecturers in this regard. The extent to which experience is gained by students during a course cannot be measured by a traditional examination either; it should be measured by evaluating the way in which students handle and solve real-world problems. In the words of Taylor-Nicodemus [10], "efficiency isn't the goal; students' understanding [and their experience of applying techniques] are. And that requires active, not passive learning." Also in support of this view, Brans and Macharis [2] make the interesting point that the way in which students 
prepare for their assessment has a strong influence on what they remember of the taught topics in a course and how they integrate these topics in their subsequent professional activities. Due to a lack of time, students often absorb the course contents very quickly before the assessment date and as a consequence of this speedy procedure they often forget everything as quickly as they had learnt it. In this context a project-driven nonexamination course on the practice of OR at Stellenbosch was clearly desirable, thereby providing OR students with a sheltered and forgiving environment for acquiring, in a very practical setting, some of the experience of applying OR techniques they need in order to enter the job market.

Brans and Macharis [2] go on to describe a very interesting experiment on the incorporation into their OR course of required theatre productions by engineering, computer science and mathematics students. Students had to apply the OR topics taught in the course to real world problems (selected by the students themselves) by means of a dramatization via the extensive use of computer software. Brans and Macharis note that the results obtained by this experiment at three universities in Europe are extremely encouraging. The students apparently exhibit strong motivation and imagine themselves being part of the real world situation. Consequently they master the topics much better than in any classical teaching and assessment procedure.

The newly introduced course on methods of OR at Stellenbosch University is by no means a "classical teaching and assessment procedure" and goes considerably further than allowing students to imagine that they are part of a real-world situation, by means of role-playing. The course consists of a number of modelling cycles during which students

- are confronted by the ruthlessly complicated and fuzzy nature of real-world OR problems during actual visits to physical application sites,

- are afforded the opportunity to model the situation mathematically in teams,

- write up their solutions in the form of written reports delivered to the role-players at the application sites,

- present their work orally in group sessions to which the same role-players in industry are invited, and

- receive feedback from the lecturers in terms of the good and bad points in their modelling and solution procedures, as well as in their presentation skills. 
These cycles are each preceded by a limited number of introductory lectures on theoretical issues that might be valuable during the subsequent project cycle.

The objectives of the course are outlined in $\S 2$ and the course structure is described in more detail in $\S 4$. Running a course like this is certainly demanding in terms of practical and administrative organisation, and hence attention is paid to this aspect of the course in $§ 3$. The underlying nature of the projects that form the backbone of the course is also discussed in this section, while the course assessment scheme is explained in $§ 5$. The paper is concluded by discussing (expected and unexpected) problems encountered during the course as well as some feedback by the students in $\S 6$ and finally, some concluding remarks in $\S 7$. A more detailed description of a sample of the actual projects used in the course follows in a separate appendix.

\section{COURSE OBJECTIVES}

As noted in $\S 1$, the main reason for introducing this course was to rectify the lack of a practical problem formulation component in the education of students in OR at Stellenbosch; hence this is obviously the main objective of the course. Also, in line with the view of applied mathematics as a modelling activity, which is fostered at Stellenbosch, giving the students modelling experience is desirable and hence the secondary objective. The other course objectives are contained in the formal course description on the Department's website [5], which reads as follows:

"This course is offered in collaboration with a number of partners in industry, who share the view that good applied mathematicians and operations researchers are bred through practical experience and should possess a number of skills in order to be successful in practice: they should have a sound mathematical background; they should be problem formulators just as much as problem solvers; they should have good interactive and people skills; they need to be computer literate; and they should be able to sell their product via the compilation of clearly understandable written reports and oral presentations."

What we mean by "problem formulation" is briefly as follows: (i) talking to people at an application site who are doing something in a way that does not satisfy them, and who are therefore looking for a better alternative; (ii) helping them to identify their objectives; (iii) helping them to identify the constraints which are active in the situation; (iv) finding out what data are available; $(\mathrm{v})$ reaching a provisional agreement as to what both parties 
will try to do. Depending upon the circumstances, further steps may follow which may lead to a fully-fledged project proposal, including time frames, deliverables and (in the case of professionals) remuneration.

Once the problem has been formulated in this sense, the mathematical modelling phase can begin. Much has already been written about the art of modelling. According to Powell [7], for example, the role of OR teachers is to build a bridge between a student's innate ability to simplify and abstract the real world in order to improve his/her understanding, and the formal skills needed to build a useful model. Baker [1] and Powell [7] list seven basic modelling skills. These are categorising variables (distinguishing between parameters, decisions and outcome measures), modularisation (decomposing a model into relatively independent parts), isolating parameters (entering a parameter in one place in a model and referring to it wherever else it is needed), establishing a base case (deciding whether to measure proposed changes against the most likely case, the current case, or the worst case), backing in (using breakeven analysis to identify a critical level for a variable), sensitivity analysis (learning which parameters have the most powerful effect on the model outcome) and pattern analysis (looking for patterns in the results to assist in translating model results into information useful to managers).

Powell [7] also mentions six more advanced modelling skills, which are prototyping (building a simple model first, testing its implications and then expanding and improving it), graphing for relationships (using a simple generic graph to suggest properties of a relationship between model variables), using families of mathematical relationships (using families of curves with few parameters, such as the demand family $Q=a P^{-b}$, to support later sensitivity analysis), imagining the answer (working backward from the desired answer to known data), understanding the data (realising that all data represent (possibly biased) samples from reality) and separating idea generation from evaluation (controlling one's critical faculty by generating ideas in an uncritical fashion). Powell [7] goes on to comment that "many of our students do not possess these skills. Much of modelling is a craft, and should be taught in a manner appropriate to craft. While this requires a different approach than teaching the scientific aspects of Management Science [and OR], it can be done."

The main objectives of the course described in this paper may now be defined in terms of the abilities that the students need in order to carry out the two broad activities (problem formulation and mathematical modelling) described above. These include:

- The ability to communicate with people in a variety of fields. Students should 
discover the importance of being patient and of formulating questions simply, yet precisely, during application site visits. They should also learn not to expect concise and exact answers to their questions.

- The ability to analyse a set of facts logically and identify the important aspects of the situation. Students should learn to sieve through a potentially large body of useless information in order to arrive at the typically small amount of crucial and meaningful information during site visits.

- The ability to abstract a mathematical structure from the verbal description of a situation. Students perhaps find this aspect of the modelling process most difficult, after articulating a verbal formulation of the problem objective(s). Students should learn to bridge the gap between the verbal formulation and the array of mathematical techniques and computational resources at their disposal, by formulating a (preferably much simplified) mathematical representation of reality. Here students should gain some confidence towards answering the question: "Which kind of mathematical model should I use for this situation?"

- The mathematical and computing skills needed to solve the resulting problem. Of course a mathematical model is worth very little if it cannot be (approximately) solved. Although the question of mastering model solution techniques is not the central aim of this course, the course draws on such techniques from a number of prerequisite courses (such as introductory courses on statistical analysis, classical optimisation and mathematical programming).

- Experience of working in groups and handling the inevitable conflicts that ensue. Interactive discussions should take place, during which conflicting psychological situations should be faced. In the words of Brans and Macharis [2], "students should learn how to mix individual ideas into collective contributions, by understanding that everybody has to contribute ideas toward the project execution and that all contributions should be fully understood and accepted by all members of the group". Students should grasp the importance of ownership of a project, which is discussed in some detail by Robson [8].

- The ability to produce a lucid report. This report - containing the verbal problem formulation, the subsequent mathematical model, its solution and a corresponding sensitivity analysis, as well as an easily understandable interpretation of the solution - should be aimed at people who are not necessarily able to appreciate mathematical 
notation or manipulation, but who are well aware of what is important to them at the application site. Students should learn how to avoid unnecessary jargon, or at least to remove excessively technical report details to an appendix.

- The verbal skills needed to present the results of the project orally in an effective way. If one cannot sell one's product it does not matter how good it is. Students should learn to present the essence of their solution clearly and in non-technical terms. They should also learn to think on their feet and respond to possibly unexpected questions or criticisms by the application site management.

\section{PRECEDING WORK}

Lecturers who contemplate offering a project-driven course like the one described in this paper should remain under no illusion as to the amount of time and effort that will be required of them. It is true that lecturers find themselves less "in front of a class" during a course such as this, but this reprieve is more than compensated for by the course demands in terms of practical and administrative organisation. Preparation for our course started a number of months in advance of actually offering the course, by considering the kinds of projects that would be on offer. This selection process was dictated by contacts in industry available to the lecturers - a resource not easily come by. Other aspects of preparatory work preceding the course included providing the necessary infrastructure and the scheduling of an appropriate time table of contact sessions.

\subsection{Selecting course projects}

The projects undertaken are the heart of the course and hence exceptional care should be taken when selecting project topics. The lecturer(s) should be very closely familiar with a project proposal before it is incorporated into the course. In our case only projects in which at least one of the lecturers had previously been involved in a consulting capacity or scaled down aspects of graduate (typically masters) projects that had previously been supervised by at least one of the lecturers were selected. In this way the lecturer in question possessed intimate knowledge of the project details, its level of difficulty, the availability of relevant data and reasonably expected project outcomes within a 3 week project time span; thereby reducing the risk of project failure during the course significantly. Of course project failure (perhaps because of an unforeseeable flaw in the project proposal or perhaps because of an unsurmountable level of project difficulty) could have catastrophic consequences on the course as a whole; not only will time and resources have 
been wasted in such a case, but more importantly, the students may have lost confidence in the course as a tool for gaining positive OR practicing experience.

The topic underpinning a project should fall within the broad range of topics usually associated with OR and the project should be open ended, in the sense that there should be no obviously right or wrong answer - thereby allowing the students freedom and encouraging experimentation with respect to objective formulation and model assumptions. That being said, it should certainly also be possible to limit the scope of a project so that it may be carried out within a reasonably short time frame (3-4 weeks).

Apart from suitability of topic and level of difficulty of a project, another criterion which was applied when considering project topics was the availability and attitude of the contact person(s) or managers at the intended application site. Cognisance was taken of whether these managers exhibited positive attitudes towards tertiary education in general and would possibly be prepared to view their participation in the course as an altruistic investment in the quality of the future workforce of the country, by generously giving of their time and making their facilities available for a site visit, whilst most likely never directly witnessing any dividends that the course might offer. Given the necessary "time is money" attitude of role-players in an often cut-throat competitive industry, it was indeed a tall order to find managers who were sympathetic towards the OR education cause. However, it was not impossible to find such managers with some effort; the way in which this was achieved was to approach managers for whom successful consulting work had previously been conducted by one of the course lecturers. It was reasoned that, if managers already had positive attitudes towards the course lecturers and/or the department/university which would be offering the course, because of a previously successful collaboration, they would be more likely to devote their time towards contributing to the success of the course.

Another important requirement for a project to be included in the course is that a suitable site visit should be possible (i.e. the site should not be too far away from the university and the contact person should have enough time available to conduct a site tour with the students). It should also be possible for the application site to provide a reasonable amount of data, to be used for the calibration and validation of mathematical models.

Once a contact in industry was secured for a site visit during the course, his role in the course was negotiated in very clear terms before the course started. In particular, the contact person knew in advance exactly when and how much of his time would be expected of him. Typically the contact person was required (i) to conduct a facility tour 
on the day of the site visit, (ii) to be available to students via telephone, fax or email for further clarification during work on the project, and (iii) to attend the final oral project delivery by the students at the university. Another important aspect clarified in advance with the contact persons was the delicate issue of availability of site data; specifically what data would be required, in what format it would be available and whether any aspects of the data were sensitive or confidential.

Finally, the summary in Table 1 should provide the reader with a clearer impression of the kinds of projects included in our course. This table shows the OR topics, application sites, problem objectives of and data required for each project included in the 2001 and 2002 course presentations. An asterisk next to a site visit duration indicates that the visit was virtual. A more detailed discussion of a selection of four of these projects is presented in the appendix.

\subsection{Providing course infrastructure}

After having identified course project topics and corresponding industrial site visits, appropriate course study material had to be found. This material, which comprised a selection of photocopied chapters from a number of OR textbooks, was chosen specifically for use during a limited number of theoretical survey-style lectures preceding each site visit. The aim of these lectures was to introduce the student to basic concepts within the broad project topic and to help students identify references for further reading when working on the projects later on, but was never so specific as to suggest a particular modelling approach during the subsequent project work - this was left to the students to discover for themselves from amongst their reading material, and they were given a free rein in this regard.

There were also a number of other matters, not usually associated with regular-style courses, that needed attention before the course started. First, transport had to be organised for each of the site visits. Secondly, short pre-site visit briefs were prepared by the lecturers, to be delivered during transporation to an application site, so that students knew what to expect at the site visits. Thirdly, students had to be educated regarding their behaviour during site visits and when communicating with site managers, since these activities were, for the most part, new experiences to them. This required preparation on the part of the lecturers beforehand, in the sense that hand-outs had to be prepared, including (i) suggestions as to the appropriate type of clothing to wear during site visits, (ii) what to take along (pen, paper, camera, etc.) on visits and (iii) a call for humility (there is nothing so damaging to the good will of a manager toward the 


\begin{tabular}{|c|c|c|c|c|c|c|}
\hline OR Topic & Application Site & Origin & Objective & Data Required & Visit & Year \\
\hline $\begin{array}{l}\text { Optimisation / } \\
\text { mathematical } \\
\text { programming }\end{array}$ & $\begin{array}{l}\text { Keerom Dam, an irriga- } \\
\text { tion reservoir for } 15 \text { wine- } \\
\text { producers near Worcester } \\
\text { (Little Karoo) }\end{array}$ & $\begin{array}{l}\text { Previous } \\
\text { consulting } \\
\text { project }\end{array}$ & $\begin{array}{l}\text { To find an optimal release strategy which } \\
\text { meets farmers' demands and satisfies legal } \\
\text { constraints, whilst minimising water loss due } \\
\text { to evaporation }\end{array}$ & $\begin{array}{l}\text { Dam shape, rain- } \\
\text { fall, evaporation, } \\
\text { vineyard sustaining } \\
\text { requirements }\end{array}$ & 8 hours & $\begin{array}{l}2001 \\
2002\end{array}$ \\
\hline $\begin{array}{l}\text { Dynamical } \\
\text { systems }\end{array}$ & $\begin{array}{l}\text { Kgalagadi Transfrontier } \\
\text { Park, on the border be- } \\
\text { tween Botswana \& South } \\
\text { Africa }\end{array}$ & $\begin{array}{l}\text { Concurrent } \\
\text { masters } \\
\text { project }\end{array}$ & $\begin{array}{l}\text { To determine whether the current culling rate } \\
\text { of lions in the park is sustainable in the long } \\
\text { run }\end{array}$ & $\begin{array}{lr}\text { Birth sex } & \text { ratios, } \\
\text { survival } & \text { rates, } \\
\text { fecundity ratios, } \\
\text { climatic data }\end{array}$ & 1 hour* & 2002 \\
\hline $\begin{array}{l}\text { Inventory } \\
\text { control }\end{array}$ & $\begin{array}{l}\text { Clickabox, a cardboard } \\
\text { box producing factory, } \\
\text { Parrow (Western Cape } \\
\text { Industria) }\end{array}$ & $\begin{array}{l}\text { Concurrent } \\
\text { masters } \\
\text { project }\end{array}$ & $\begin{array}{l}\text { To determine optimal re-order levels and } \\
\text { order quantities meeting seasonal demand, } \\
\text { whilst minimising wastage due to off-cuts }\end{array}$ & $\begin{array}{l}\text { demand data (di- } \\
\text { mensions \& quanti- } \\
\text { ties) }\end{array}$ & 3 hours & $\begin{array}{l}2001 \\
2002\end{array}$ \\
\hline $\begin{array}{l}\text { Job shop } \\
\text { scheduling / } \\
\text { simulation }\end{array}$ & $\begin{array}{l}\text { Loubser Wood Compo- } \\
\text { nents, a wood product } \\
\text { factory in Kraaifontein } \\
\text { (Western Cape Industria) }\end{array}$ & $\begin{array}{l}\text { Concurrent } \\
\text { masters } \\
\text { project }\end{array}$ & $\begin{array}{l}\text { To identify and resolve bottlenecks which oc- } \\
\text { cur on the factory floor as a result of poor task } \\
\text { scheduling }\end{array}$ & $\begin{array}{l}\text { machine types \& } \\
\text { capacities, demand } \\
\text { data }\end{array}$ & 1 hour* & 2002 \\
\hline $\begin{array}{l}\text { Optimal } \\
\text { control theory }\end{array}$ & $\begin{array}{l}\text { SAFCOL offices in } \\
\text { Jonkershoek, Stellenbosch }\end{array}$ & $\begin{array}{l}\text { Previous } \\
\text { honours } \\
\text { project }\end{array}$ & $\begin{array}{l}\text { To determine optimal tree thinning policies } \\
\text { which maximise total nett present value of all } \\
\text { future revenues from a number of wood classes }\end{array}$ & $\begin{array}{l}\text { growth rate, wood } \\
\text { volume vs tree } \\
\text { height, wood prices }\end{array}$ & 2 hours & 2001 \\
\hline$\overline{\mathrm{MCDA}}$ & $\begin{array}{l}\text { Helderberg Municipality } \\
\text { (Cape Metropol) }\end{array}$ & $\begin{array}{l}\text { Previous } \\
\text { honours } \\
\text { project }\end{array}$ & $\begin{array}{l}\text { To determine a fair allocation of funds to a } \\
\text { number of projects contemplated by the mu- } \\
\text { nicipality within a certain budget }\end{array}$ & $\begin{array}{l}\text { budget, building } \\
\text { costs, criteria for } \\
\text { evaluation }\end{array}$ & 1 hour* & 2001 \\
\hline $\begin{array}{l}\text { Critical path } \\
\text { methods }\end{array}$ & $\begin{array}{l}\text { Francois Viviers \& Asso- } \\
\text { ciates }\end{array}$ & $\begin{array}{l}\text { Personal } \\
\text { contact }\end{array}$ & $\begin{array}{l}\text { To schedule in detail a large shopping mall } \\
\text { building and housing project }\end{array}$ & $\begin{array}{l}\text { scheduling compo- } \\
\text { nents \& their du- } \\
\text { rations, precedence } \\
\text { list }\end{array}$ & 1 hour & 2001 \\
\hline
\end{tabular}


course than an arrogant student who implies, by his attitude, that the academic world has all the answers that industries might possibly seek). Fourthly, students needed some coaching with respect to writing reports (specifically, hints on writing style) and delivering oral presentations (specifically, hints on the use of multimedia supporting equipment), and material to this end also had to be prepared by lecturers before the course started. Finally, students needed some advice on how to function as a group. They were warned in advance that, when working closely in a group, tempers might flare, opinions might differ and conflict might occur as a result. The group leaders, in particular, welcomed suggestions on how to schedule a project, what to look out for, how to delegate tasks and how to defuse potential conflict situations amongst group members. Material on these aspects of group dynamics were also prepared by the lecturers before the course started.

\subsection{Scheduling contact sessions}

The course consisted of five types of contact sessions, namely ordinary lectures, site visits, scheduled group discussions, project delivery sessions and feedback sessions by the lecturers, as will be discussed in more detail in the next section. All of these had to be scheduled well in advance of the course, because of the tight schedules of the contact persons in industry. Furthermore, there was a specific order in which these sessions had to be scheduled in cycles (theoretical lectures had to precede site visits, which had to precede group discussions, and so on). Finally, enough time had to be allowed for the site visits, and this of course had to fit in with predetermined timetables of the lecturers and the students (from various departments). All of this made for a rather tough and rigid course timetabling problem, leaving relatively little scope for postponement or date changes if certain aspects of the course fell behind schedule.

\section{COURSE STRUCTURE}

As mentioned in the previous sections, our course is project driven. The projects were all conducted in groups, each group consisting of between four and six students. For each project the students chose a group leader, who served as project manager for the duration of that project.

In order for the group leaders to know what was expected of them, we started the course with a number of introductory lectures, before the first project commenced. During these lectures, the students were introduced to the basic principles of project management. Topics of the other introductory lectures included a broad overview of basic statistical analysis, enabling them to perform elementary stochastic data analyses (most of the 
students already had some background in statistics and stochastic modelling), and basic tips on how to approach an application site problem in general (for example, what to do during the site visit, how to write and what to include in a preliminary report, what type of final presentation to prepare, etc). During these lectures the previously prepared material (discussed in §3.2) was used.

After the initial introductory lectures, the course proceeded in repeated project-driven cycles, each cycle focusing on some selected OR topic, as dictated by a physical application site. A project cycle consisted of five phases, as outlined in Table 2, with a typical total time span of 3-4 weeks. The phases of the project cycles were scheduled in the order in which they appear in Table 2. The 2002 run of the course comprised four projects, and although we attempted to limit the completion times of each phase per cycle as shown in the table, we were not always able to realise these aims (as will be discussed further in $\S 7)$.

\begin{tabular}{c|l|r}
\hline$\S$ & Activity & Time / cycle \\
\hline 4.1 & Theoretical background lectures & 4 hours \\
4.2 & Site visit & 3 hours \\
4.3 & Active group work by students & 26 hours \\
4.4 & Oral project delivery & 1 hour \\
4.5 & Scheduled feedback by lecturers & 1 hour \\
\hline & Total per cycle & $\mathbf{3 5}$ hours \\
\hline & Total for the course & $\mathbf{1 4 0}$ hours \\
\hline
\end{tabular}

Table 2: Estimated time frame for the course.

Each of the project cycle phases listed in Table 2 will now be discussed in more detail under the section headings shown in the table.

\subsection{Theoretical background lectures}

The introductory lectures scheduled at the start of each project cycle were survey-style lectures, which covered a number of chapters from suitable textbooks (as discussed in $\S 3.2$ ) and only served to provide a broad overview of a specific OR topic (such as inventory theory, optimal control theory or dynamical systems, for example). Often these lectures were on topics that students had already encountered in previous (possibly undergraduate) courses. Students were encouraged to do further reading and to experiment by generalising or adapting models discussed during these lectures so as to suit their needs during a specific application. The authors took turns to preside over project cycles, by presenting all the lectures in a given cycle. 


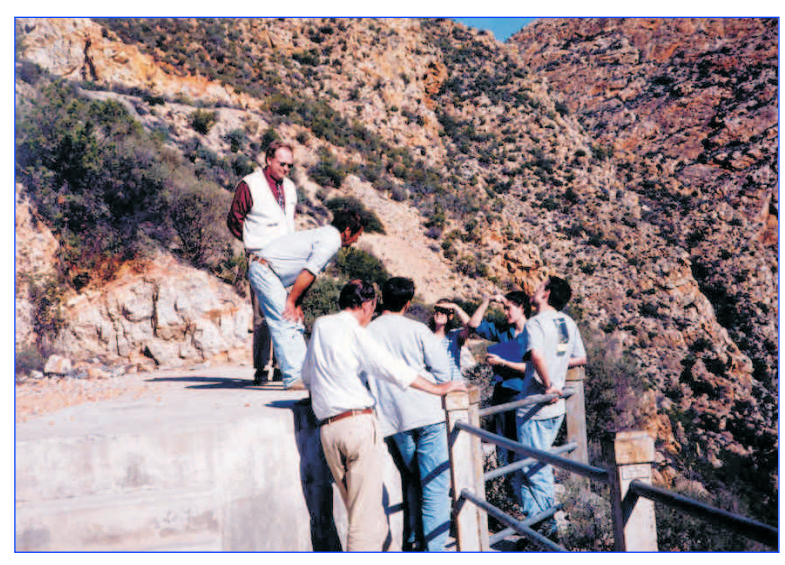

(a) Site visit at Keerom Dam, Worcester.

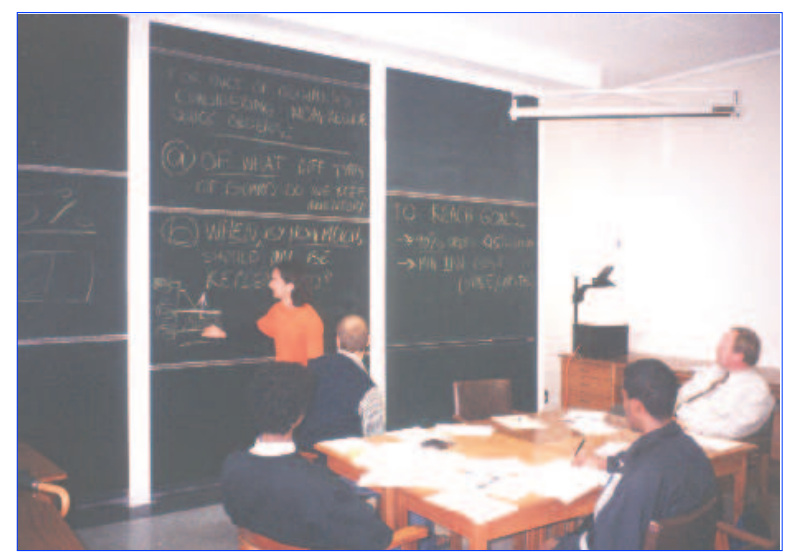

(c) A group discussion after a site visit.

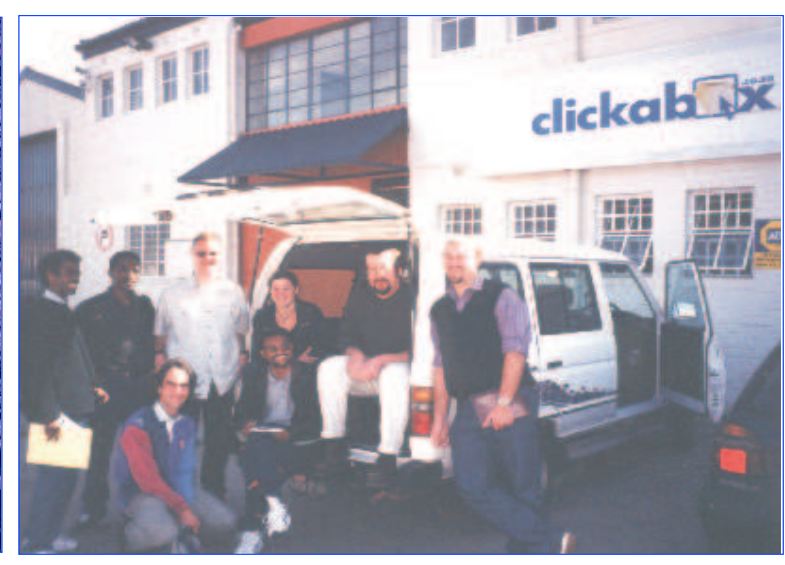

(b) Site visit at Clickabox.

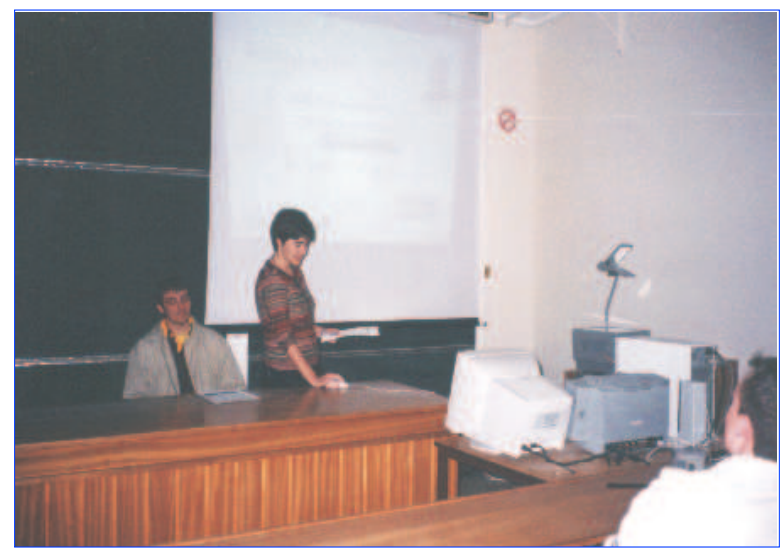

(d) An oral project delivery.

Figure 2: A few photographs from the 2001 and 2002 course runs.

\subsection{Site visit}

During the site visit, students were expected to determine what the actual problem experienced at the application site was, and then to seek out relevant information which would eventually help them to solve this problem. In order to facilitate this process of information gathering, the contact person at the site (or possibly one of the lecturers, if nobody at the site was available) conducted a brief site tour. During this tour students were allowed to question the contact person, all the while making notes. The students were also encouraged to write a preliminary report about information gathered during the site visit as soon as possible after the site visit, which would then be faxed to the contact person for comments. This was done (i) to emphasise the importance of communication with the contact person after the visit, (ii) to avoid later misunderstandings about the details of the project, and (iii) to help students understand possible site jargon to the 
extent that blending of problem specific knowledge and OR knowledge could occur, before the actual mathematical modelling part of the project began (as emphasized by Čibej $[4])$.

\subsection{Active group work by students}

After the site visit the students worked in their groups on the project. They did this mostly on their own, under the auspices of the project group leader. However, during the first contact sessions immediately after the site visit, the students conducted two officially scheduled group discussions. This was done so as to encourage them to write down and discuss all the information gathered at the site visit before they forgot too much (this information would then be assimilated into the preliminary report sent back to the contact person for clarification). Since these two scheduled group sessions occurred at an early stage in the project cycle, the students mostly spent this time doing project planning, and discussing what assumptions they should make and which kind of mathematical model would be appropriate. The lecturers attended these two group sessions, mainly for observation purposes (to help them during the subsequent project assessment phase), but if they realized during these group discussions that the students were being too ambitious for a 3-4 weeks project time span, the students were helped to scale down their expectations to a realistic level, by means of suggested simplifications or ommissions. During both the 2001 and 2002 runs of the course the lecturers often had to intervene in this way.

Interestingly enough, Brans and Macharis [2] note that it is when students begin to divide up the tasks amongst their group members, that some psychological problems may occur. We also noticed this and found that it was often the first time that the students had been required to work in groups. In each group they discover leaders as well as weaker personalities. The leaders typically motivate the others to do their tasks as well as possible, while the others merely do what is required of them. The students continually have to seek a balance between coordination and dominance. Despite the fact that not every member of the group actively partakes in the modelling phase of the project, or uses computer software to solve the group's model to the same extent as others in the group, everybody learns to work in teams. During the 2002 run of the course tempers flared dramatically because of friction in the groups, due to different levels of computer literacy of group members, language barriers and even mild forms of xenophobia (there were a number of international students attending the course). This is natural when people have to work closely together for an extended period of time, but we realised the importance 
of warning students in advance of this possibility, so that they need not perceive a project to be going horribly wrong when conflict did indeed occur.

During the normal steps of the model building process, the students got a "fair deal of collecting reliable, unbiased data so as to learn about the dirty details far beyond the beautifully prepared data in textbook exercises" [4]. The students certainly learned that the acquisition of data was not a trivial task and that they could not just expect data to be forthcoming. Often the data were not available electronically or else not in the format students had expected, and this gave rise to considerable data formatting exercises in some cases, or revised modelling approaches in other cases. It was surprising to witness the enthusiasm of the students when discussing which assumptions they would be making for their modelling approach. Here the lecturers often observed sharp differences of opinion, usually leading to a considerable amount of time being spent on trying to convince one another of various views.

\subsection{Oral project delivery}

An important aspect of practical consulting work is the ability to deliver lucid project presentations and written reports in a way that is understandable to the normally nonmathematically oriented contact person in industry. For this reason we scheduled a formal project delivery session at the end of each project cycle to which we invited the contact person(s) as well as other graduate students of our department. The students enrolled for the course were required to hand in individual written reports on the project as well as partake in a group oral presentation of the project. At the end of (and sometimes during) the oral presentations the lecturers as well as the industry contact person(s) and other graduate students would ask questions on different aspects of the project. Although we encouraged the students to deliver multimedia presentations, our view is the same as that of Čibej [4], in that the beauty of the presentation should not hide the weak points of the methods themselves. We further encouraged the students to prepare handout notes before the presentation. We also video-taped the entire oral presentation and ensuing question session, to facilitate meaningful feedback by the lecturers.

\subsection{Scheduled feedback by lecturers}

Each project cycle was concluded with a scheduled feedback session. During the feedback session the lecturers would focus on commenting about the group's (i) chosen mathematical approaches toward solving the problem at hand, (ii) the validity and acceptability of the group's modelling assumptions and (iii) the quality and applicability of the model 
solutions.

Great emphasis was placed on the question: "So, what is the bottom line of the model solution in a practical sense?" Students were not allowed to conclude a presentation or written report with a single, theoretical optimal answer. The solution had to be interpreted in a very practical sense, and was required to contain more than one alternative, clearly indicating the price to be paid if a sub-optimal solution were to be implemented at the application site, due to, say, policy or legal constraints. It is common knowledge that sensitivity analysis is an essential component of any thorough operational analysis, and students were therefore encouraged to perform not only parametric sensitivity analyses, but also structural sensitivity analyses, since most fundamental errors often come from ill-considered structural assumptions [3]. The lecturers consequently spent a significant proportion of time during feedback sessions commenting on the quality and meaningfulness of sensitivity analyses performed by the groups.

Finally, feedback was also given on project development skills in general (including how students handled the site visit, the relevance of their questions, the group interaction during the official discussions), presentation skills and the composition of the written reports. The videos made during the presentation sessions were used during the feedback session to illustrate the effects of certain (desirable and undesirable) presentation techniques as well as to evaluate the contents of the presentation with respect to the original problem posed by the contact person(s). At first the students found it slightly embarrassing, but later extremely rewarding, seeing themselves in action. They often could not believe the things they did and said during the presentations. This practice of showing the presentation video to the whole class was handled with due care, making sure not to ridicule or single out individual students.

\section{ASSESSMENT SCHEME}

The authors found it extremely difficult to find a fair assessment scheme for this course. When the course was first presented in 2001, the first project was evaluated in four separate parts: the site visit, group discussion, the final report (including the oral presentation) and each member's individual report. For the site visit, each lecturer awarded a mark for each student's contribution, and these were averaged in an attempt to filter out bias; the same was done for the other three assessments parts. Each student was also asked to assess each group member's separate contribution, in the form of percentages; the lecturers did the same. The final mark was then calculated as a weighted average, 
after which the marks were scaled according to the students' relative contributions to the project as a whole. After the first project, the assessment of the site visit was discontinued, as this tended to lead to staged performances by the students during the visits, with the students competing to see who could ask the most intelligent questions.

In 2002 the marking scheme was simplified greatly. The preliminary reports and the quality of the group's modelling approaches (including the oral presentation) were evaluated for the group as a whole, and the individual reports for each student separately. The final mark was calculated as

$$
\begin{aligned}
\text { Final mark }= & \quad 0.05 \times \text { group preliminary report mark } \\
+ & 0.45 \times \text { group project mark } \\
+ & 0.5 \times \text { individual report mark. }
\end{aligned}
$$

In retrospect, this scheme gave too little weight to each individual's contribution. A student could choose not to take part in all the activities (for instance never partaking in an oral presentation), but still obtain a higher mark than another who had taken part in every activity. The optimum assessment scheme probably lies somewhere between the 2001 and 2002 schemes in terms of level of detail.

\section{COURSE EVALUATION AND STUDENT FEEDBACK}

A critical mistake when offering a course like this is to allow too many students to work in a group; this causes a lack of project ownership and hence a lack of full participation by some group members. In 2001 six students enrolled for the course, and they always functioned togther in a single group for the duration of the course. In 2002 nine students enrolled for the course, and they were divided into two groups (one of four and one of five students) of varying composition. We found that six students is the absolute maximum, but that four seems to be the ideal group size. In terms of practical administration (such as the number of group presentations lecturers have to sit through and the number of individual group feedbacks that have to be prepared by lecturers), it is also necessary to limit the number of groups (and hence the number of students that register for the course). We found that two groups is the absolute maximum, but that a single group seems to be ideal.

The site visits, in themselves, can give rise to various problems. First, in one specific instance, the site visit had to be postponed until further notice one day before the actual visit should have taken place, because of road damage cause by bad weather conditions. 
This event put the carefully planned course timetable under pressure, and there seems to be no real solution to this dilemma. Another problem that occurred is that the site of an excellent project for the 2002 course was impractically far away from the university $( \pm 900 \mathrm{~km})$. This problem was overcome by arranging a virtual site visit in television documentary style, using multimedia as explained in $\S \mathrm{A} .2 .2$, but this solution is not desirable, since it detracts from the course objective to provide the students with a sense of realism - closer application sites should be chosen instead.

One rather serious mistake we made was to underestimate the volume of course work. We started out with five project cycles during the 2001 course, reduced this number to four in the 2002 course; and plan even further reductions in future. We also found that one should allow the students just enough time to achieve a workable solution to the site problem: if one grants extensions (for example, to accommodate concurrent commitments by the students, such as busy times around tests and examinations) the students tend not to balance their project work effectively with other work; they typically prefer to let the project grow larger, as "more time" is available, instead of studying for other courses. On the other hand, it is also possible to overestimate the workload. In one case in 2002, we chose a job shop scheduling project at a wood production plant, where bottlenecks were experienced as a result of poor scheduling (as descibed in more detail in $\S$ A.4). The course lecturers had been involved as project supervisors in two MSc modelling projects at this plant since 2001, and were well aware of the magnitude of the project. The objective of the problem was to simulate (via computer) the production process, using stochastic order arrival times and quantities (derived from historical order data) with a view to identifying expected bottlenecks. Furthermore, based on the expected severity of these bottlenecks, the company was reportedly interested in the potential benefit of additional investment in infrastructure so as to reduce bottlenecks and hence overtime. In order to scale down this problem to one that could be handled as a 3-4 week project in the course, the authors divided the factory floor into two subfactories and allowed each of two groups to solve the original problem on the separate (smaller) subfactories, cutting back on the number of different production sequences. What we did not foresee was that in one subfactory these simplifications caused a cessation of bottlenecks altogether. Although this particular group could therefore not reduce bottlenecks, they still came up with a way to determine more realistic makespans for that part of the factory, thus changing the original objective of the project. We learnt that the scaling down of projects is a dangerous and tricky business, easily trivialising the problem in a subtle way. 
An idea that worked very well was to select parts of concurrent OR masters projects in our department as course projects, instead of merely selecting projects on the basis of previous consulting experiences. In this way, the masters students could often benefit from the course by incorporating bright ideas of the groups. Conversely, the masters students could also play the role of the contact person(s), conducting site visit tours in order to save the valuable time of our industry partners.

The method of assessment for this course remains an unsatisfactorily resolved problem. The first time the course was presented in 2001, the students were asked to indicate the relative weights of their own contributions towards the project, as well as those of their colleagues. These weights were then used during the assessment phase, as described in $\S 6$, but this did not work well, since the students did not want to penalise their fellow students (and typically assigned equal weights to all in the group). The aspect of relative contributions to the success of projects was ignored during the subsequent 2002 course in a bid to sidestep this problem, but this led to other problems, such as allowing students not to take ownership of projects, lying low with relative ease. No completely satisfactory assessment scheme has as yet been devised for the course.

On the topic of project delivery, Brans and Macharis [2] make the interesting point that in a classical teaching and assessment regime, the lecturer has an advantageous or strong position, and that the student occupies a more or less weak position, depending on his knowledge of the course contents. A lecturer can always bring the student into difficulties by asking hard questions. However, a group delivery of a project inverts this social relation. The students are now in a strong position, because they know all about their modelling approach, while the lecturers have to discover it during the presentation and subsequent study of the individually written reports. We found that this boosted the confidence of the students significantly, leading to more than one remark along the lines of students being pleasantly surprised by the fact that they never knew they were capable of practical modelling before taking the course. This may possibly be interpreted as an indictment in a department where strong emphasis is placed on modelling in all courses. Alternately, this may be viewed as a result of the current course not covering work in which there are definitely right or wrong answers. Whatever the case may be, both presentations of the course were observed to boost students' confidence in their abilities as modellers and problem solvers.

In the end, the bottom line is: what do the students gain (or perceive to gain) from a project-driven course like the one described in this paper? A few quotations follow from 
students who have taken the course:

- SB: No other course gives as good a reflection of practical OR. For a student the experience is invaluable.

- ML: I also learned about group dynamics and developed confidence in approaching practical problems.

- DC: An integral part of any future operations researcher's training. As a scientist you learn how to interact with the public.

- WG: Covers all stages of the mathematical modelling process, which makes it essential for the development of any applied mathematician.

- LT: The most negative of the course was that it was very time consuming, especially because of communication difficulties and different levels of computer literacy, but through this we really experienced the reality of team work. On the positive side, I gained more confidence in approaching real life practical problems.

\section{CONCLUSION}

In this paper a new, project-driven course on "Methods of OR," which has been running for two years at Stellenbosch University, is described. The objectives and structure of the course are documented and motivated in detail. The nature of the projects used are outlined, and some project specifications are given in detail in an appendix. The authors view the overall success of and student benefit from the course in a positive light, although certain mistakes and negative aspects were acknowledged in the paper. It is the hope of the authors that the information in this paper might inspire or facilitate similar courses elsewhere. However, one should not underestimate the amount of energy that lecturers have to put into offering a course like this.

\section{ACKNOWLEDGEMENTS}

The authors are endebted to Elise del Rosario, who inspired the idea of a real-life projectdriven OR course in the first place. The development of the course described in this paper was supported by the South African National Research Foundation under grant number GUN 2053755, as well as by Research Sub-committee B at the University of Stellenbosch. 
Any opinion, findings and conclusions or recommendations expressed in this paper are those of the authors and do not necessarily reflect the views of the National Research Foundation or the University of Stellenbosch.

\section{References}

[1] K. BAKER, Gaining insight in Linear Programs from Patterns in Optimal Solutions, INFORMS Transactions on Education, 1(1) (2000), [Online], [Cited 2003, January 8], Available from http://ite.informs .org/vol1no1/baker/baker.html

[2] JP Brans \& C Macharis, Play theatre A new way to teach O.R., European Journal of Operational Research, $\underline{99}(2)$ (1997), 241-247.

[3] JP Caulkins, When Parametric Sensitivity Analysis Is Not Enough, INFORMS Transactions on Education, 1(3) (2001), [Online], [Cited 2002, October 9], Available from http://ite.informs.org/vol1no3/caulkins/caulkins.html

[4] JA ČIBEJ, Operations research education for forgotten populations, European Journal of Operational Research, 140(2) (2002), 225-231.

[5] PduT Fourie, I Nieuwoudt \& JH van Vuuren, Methods of $O p$ erations Research [Online], [Cited 2002, December 27], Available from http://dip.sun.ac.za/ vuuren/MethodsOfOR/index.php

[6] WR GRÜNDLINGH \& JH VAN VUUREN, An active decision support system for optimality in open air reservoir release strategies, International Transactions in Operational Research, $\underline{8}$ (2001), 439-464.

[7] SG Powell, Teaching Modeling in Management Science, INFORMS Transactions on Education, 1(2) (2001), [Online], [Cited 2002, October 9], Available from http://ite.informs .org/vol1no2/powell/powell.html

[8] M Robson, Problem-solving in Groups, Technical Text Ltd, Oxfordshire, 1988.

[9] EA SILver, Designing and Delivering a University Course - A Process (or Operations) Management Perspective, INFORMS Transactions on Education, 2(1) (2001), [Online], [Cited 2002, October 9], Available from http://ite.informs.org/vol2no1/silver/silver.html 
[10] N Taylor-Nicodemus, Confessions of a Teaching Workshop Skeptic, The Teaching Professor, $\underline{6}(4)$ (1992), 5-6.

[11] JH van Vuuren, E Herrmann \& P Funston, Lions in the Kgalagadi Transfrontier Park: Modelling the effect of human-caused mortality, International Transactions in Operational Research, to appear.

\section{Appendix: PROJECT EXAMPLES}

In this section we describe four examples of projects included in the 2001 and 2002 presentations of the course. In each case we describe the practical situation at the application site, the OR techniques presented to students during lectures (before the site visit), the methodological approach eventually adopted by the students and the overall outcome and success rating of the project.

\section{A.1 MATHEMATICAL PROGRAMMING: RESERVOIR CONTROL}

\section{A.1.1 Site background \& problem}

Keerom Dam is the second largest privately owned reservoir in South Africa. It is situated in the Keerom Mountains about fifteen kilometres outside Worcester and serves the Nuy valley in the semi-arid wine producing region of the Little Karoo, which is a winterrainfall region. The reservoir was built in 1954 by a group of 15 farmers in the Nuy valley to enable them to accumulate and store water during the relatively wet winter months (May-September). These reserves may then be utilised during the dry summer months (especially December-March), during which rainfall is not sufficient for sustaining their vineyards. The offspring of these reservoir-pioneering farmers today manage the reservoir via an annually elected board of six farmers, who take decisions on a bi-weekly basis as to when and how much the reservoir's sluice openings should be adjusted. Their objectives are, somewhat imprecisely speaking, twofold: (i) to minimise annual water loss due to excessive amounts of evaporation, and (ii) to meet irrigation demand during the hot summer season.

The objectives listed above are, of course, conflicting, and hence the bi-weekly Keerom Dam board meetings were characterised by heated debates and disagreements as to what constitutes a good reservoir management strategy. This situation of conflict was alleviated somewhat by a research project during the period 1997-1999 in which one of 
the course lecturers developed an active decision support system for the board of management. The support system takes as input climatic conditions, the observed rainfall pattern and reservoir content profile up to a certain point in the hydrological year, and rainfall expectations for the remainder of the year. It delivers as output a suggestion with respect to the release rate that would first meet expected irrigation demand and then aim to minimise expected evaporation losses. The system revises and updates its decision support suggestions as the hydrological year proceeds and more climatic data become available. More information on the problem and the decision support system may be obtained from [6]. Although this system was installed at various work stations throughout the Nuy valley and is currently in use by the farmers, the system details were withheld from the students. However, during the course of research for this decision support system the course lecturers gained valuable insights into the subtleties of the decision problem experienced by the farmers and also took time to obtain (i) rainfall data and evaporation rates for the region experienced over the past 50 years from a weather station close to the reservoir, (ii) irrigation requirements per hectare of vineyard from the KWV Corporate Winery, and (iii) reservoir parameters (such as its shape, height, capacity) from sonar images constructed by civil engineering company Ninham Shand, Inc. By the time the course was first presented during 2001, the lecturers were therefore one step ahead of the students in their understanding of the problem, and were also in a position to supply the students with data as and when requested by them.

\section{A.1.2 The site visit}

In both the 2001 and 2002 courses the site visit was basically a whole day affair. Students were taken in a university bus to the reservoir, a two-and-a-half hour drive from the university, where one of the farmers presented them with (a somewhat biased) view of the decision problem at hand. Students scaled the 27 metre high flood walls, visited the sluice controls and were provided with a picnic lunch, while continuously bombarding the participating farmer with questions about the reservoir, the farmers' disagreement, the way in which vineyards are irrigated, climatic conditions of the region, etc. During all of this the lecturers were present more or less as silent witnesses, assessing the group dynamics and the quality of interrogation.

\section{A.1.3 Theoretical background}

This project was scheduled very early in the course. No lectures were delivered as part of the course to prepare students for the project, but a course on mathematical programming, running during the previous semester, was a prerequisite to this course. Topics 
considered in the prerequisite course included linear programming (the simplex method, conducting sensitivity analyses, use of shadow prices, duality and the dual theorem, complementary slackness, etc.), dynamic programming (principle of optimality, backward and forward recursion, shortest and longest paths in a network), multiple-objective programming (goal programming) and integer programming (the branch and bound method, the method of implicit enumeration and the cutting plane method applied to a number of knapsack and combinatorial optimisation problems).

\section{A.1.4 Outcomes and success rating of the project}

In 2001 the student group developed a linear programming model to determine a sluice release strategy which would minimise total expected evaporation losses, subject to vinyard sustainment and legal requirements. One of the 2002 groups adopted a similar, but slightly more flexible mathematical programming model, while the other 2002 group took an interesting common sense modelling approach towards the problem, based on optimal control theory. All three groups produced work of high quality, impressing two of the Nuy farmers invited to the university for the oral presentations. During these presentations the farmers inflicted certain serious points of criticism on the students' work, but they seemed to stand their ground fairly well, to the point of even convincing the farmers of reversing their views on certain issues. The authors view this project as very successful; the students seemed to enjoy it immensely (perhaps because it was still early in the course) and certainly learnt a lot about practical modelling, particularly about the convincing power of sensitivity analysis results during presentations.

\section{A.2 DYNAMICAL SYSTEMS: BIOLOGICAL SPECIES SURVIVAL}

\section{A.2.1 Site background \& problem}

Predation on domestic livestock by large predators from conservation areas bordering rangelands is a major cause of conflict between farmers and conservation organisations. In particular, large carnivores, such as lions (Panthera leo), have decreased substantially in number during the last few decades as a result of increasing pastoralism and conflict along the boundaries of the Kgalagadi Transfrontier Park (KTP) on the border between South Africa and Botswana. Lions in the KTP have been subject to regular persecution by neighbouring farmers in defence of their livestock herds for several decades. Most cases of such depredation occur when the lions break through the fencing that separates the KTP from the neighbouring farming areas and kill free-ranging livestock, particularly in Botswana. In retaliation, livestock owners follow up virtually all incidents of depredation, 
mostly with the intention of destroying the lions before they can return to the safety of the park, from where they may launch future attacks.

During the period 1998-2001 alone, for which detailed records exist, more than a hundred lions have transgressed the boundaries of the park, of which almost a third were shot. Numerically, adult lionesses and their young comprise the largest proportion of the population that transgress, followed by sub-adult and adult male lions. Following a population census conducted in 1976, concern was raised that the population may be negatively affected by such persecution, which led to a second population survey some twenty years later. In contrast, results from this second survey suggested that there had been only a marginal decline in the number of lions. Observations indicate that the population is currently at a demographic level somewhere between these two estimates, raising questions about the long-term sustainability of the lion population residing within the boundary areas of the KTP. However there seems to be disagreement between conservationists (who view the problem as potentially serious) and government as well as park management officials (who are loath to earmark resources from already constrained budgets in order to resolve a problem not experienced to be a most pressing need). The following three questions were posed, in order to decide on the nature of action to be taken (if any):

1. To what extent is the KTP boundary lion population able to increase its chances of survival by inducing birth sex ratio biases under different environmental conditions (as has been observed to happen)?

2. How sensitive are KTP boundary lion demographic equilibria with respect to increases in age class specific human-caused mortality under different environmental conditions and subject to birth sex ratio biases?

3. What is the maximal age class specific human-caused mortality rate that the KTP boundary lion population is able to sustain under different environmental conditions and subject to birth sex ratio biases?

More information on this problem may be obtained from [11].

\section{A.2.2 The site visit}

Since the KTP is approximately 900 kilometres from the university, students could not be taken on a site visit, as with other projects in the course. Therefore they were taken on a virtual visit during the 2002 course cycle by means of a PowerPoint presentation by one of 
the lecturers. Considerable effort was put into the presentation in an attempt at making the visit as realistic as possible, by including many photographs of the region and animals in question, and by presenting the students with an impression of the geography and climate of the region as well as the biology of lion demographics in television documentary style. The students were afforded ample opportunity to question the presenting lecturer in order to get a grip on the problem, as if the lecturer were a park ranger or site contact person. Fortunately the lecturer had been involved in a masters modelling project on the KTP lion population during the previous year, in the capacity as project supervisor. He was therefore in a position to deal with students' questions after the presentation in a seemingly expert fashion, by drawing on problem experience and data gathered the previous year. As a result of the presentation the students gained a good understanding of the situation, and exhibited the kind of excitement noticeable after a real project site visit.

\section{A.2.3 Theoretical background}

The virtual site visit was preceded by a number of lectures on matrix models of population demography. Topics considered included an introduction to discrete dynamical systems, simple Leslie-type matrix models, the Perron-Frobenius Theorem (and how it is used to determine population stability), and the incorporation of stochasticity into models via computer simulation.

\section{A.2.4 Outcomes and success rating of the project}

This project was introduced into the course during 2002, and both student groups developed matrix-type demographic models in order to attempt answers to the three questions posed by the KTP management. A park assistant, who was also a part-time masters student at the department, was invited to the oral presentations and seemed pleasantly surprised by the students' work. He felt that their conclusions were carefully motivated and seemed plausible from a practical point of view, despite a considerable amount of fuzziness and possible inaccuracies in the data. The authors viewed this project as a very successful part of the course.

\section{A.3 INVENTORY CONTROL: CARDBOARD BOX PRODUCTION}

\section{A.3.1 Site background \& problem}

Clickabox is a relatively small factory (located in the Parow Industria of the Cape Peninsula, about 5 minutes from Cape Town International Airport) that manufactures card- 
board boxes at very short notice and hence at a slightly higher price than well known, larger suppliers, such as Nampak or Mondi. Although Clickabox clients are mainly based in the Western Cape, occasional deliveries are sent by air to other parts in the country. The company occupies a niche in the market where it competes on virtually immediate availability of products, rather than on quantity or price. The name of the company derives from its high degree of integration into an interactive internet website through which it conducts its business. The factory has to be able to react rapidly to orders; hence good management of its inventory system is absolutely essential.

The business activities of Clickabox may be broken down into 8 principal components. The first component involves marketing. This is done on the internet, in the yellow pages, by means of marked delivery vehicles and word of mouth spreading of client satisfaction. The second and third components are handled electronically via the interactive Clickabox website. These components entail replies to quote requests and the actual ordering of boxes (or uncut board in some cases). The website then issues a job card electronically, after which the fourth component, namely manufacturing of the order, is initiated. The manufacturing process consists of a number of subsidiary activities, such as cutting down cardboards to the desired box sizes, printing emblems and other matter on the boards, gluing or stitching of boards to produce finished boxes, and finally strapping together boxes so as to make up orders of the desired quantity. Once an order is complete, it is delivered to clients, which constitutes the fifth business component. This is of course followed by payment for the order, after which Clickabox is able to pay its suppliers (such at Nampak or Mondi) and to pay out salaries to its floor workers and office staff (the sixth, seventh and eighth business components respectively).

\section{A.3.2 The site visit}

In both the 2001 and 2002 courses the site visit lasted in the region of two hours. Students were taken in a university bus to the factory, about a half hour drive from the university, where the manager and owner of the company took students on a fascinating production floor tour, explaining in detail each stage in the production process. Students frequently interrupted the tour with numerous questions on inventory management decisions, technical questions about cardboard boxes, company finances, etc. During the course of the visit the manager summarised to students what he perceived the objectives of the project to be. These were to build a mathematical model by which the company would be able to increase their capability of meeting orders to more than $90 \%$, while simultaneously inducing no more than $15 \%$ off-cut wastage. He stressed that this should be achieved by 
reducing stockholding to a minimum (i.e., holding only good board sizes and then only good quantities of these good sizes). Quite a tall order!

Again, one of the lecturers was involved in a masters modelling project on the Clickabox inventory problem during the previous year, in the capacity as project supervisor. He (and the masters student) were therefore in a position to deal with students' questions in the aftermath of the site visit, by drawing on their problem experience and data gathered during the previous year. In addition the company manager was also available to answer questions in the event that the lecturer was unable to handle questions.

\section{A.3.3 Theoretical background}

The site visit was preceded by a number of lectures on optimal inventory control. Topics considered included the basic Economic Order Quantity (EOQ) inventory model, computing optimal order quantities when quantity discounts are allowed, the continuous rate EOQ model, single-period decision models (incorporating the use of marginal analysis), the news vendor problem (with both discrete and continuous demand) and the EOQ model with uncertain demands (the $(r, q)$-model, the $(s, S)$-model and the service level approach to determining safety stock demand).

\section{A.3.4 Outcomes and success rating of the project}

Although this project was introduced into the course in 2001, the 2002 student groups did exceptionally well in this project. Both groups developed surprisingly detailed inventory models, involving a considerable amount of data-analysis beforehand. Their models were able to show that the owner's figures of meeting at least $90 \%$ of orders on time with at most $15 \%$ off-cut wastage, were incompatible, given the limitations of his storage area. They were able to present the owner with estimations of the best trade-off curve between these numbers, providing him with re-order level and quantity strategies in the form of simple look-up tables. Not only was the owner impressed by the analysis, he also implemented aspects of the model solution; something neither he nor the course lecturers expected as outcome of this course project. The masters student even benefited from some of the course students' ideas. This is perhaps one of the most successful projects we have included in the course so far.

\section{A.4 JOB SHOP SCHEDULING: BOTTLENECKS AT A WOOD FACTORY}

\section{A.4.1 Site background \& problem}

Loubser Wood Components, Inc. is a small-scale wood panel producing factory in the 
Kraaifontein Industria of the Western Cape. The company is managed and owned by three brothers, aided by a secretary and a factory floor workforce of 19 workers. The plant produces wooden panels for doors and other furniture, and depending on the type of panel, the production job card for a certain order may contain different tasks to be performed in possibly different orders. There are a number of possible tasks (such as sanding, ripping, sawing, spray painting, etc.) that are performed on 15 different machines (such as an edge bander, panel saw, spray booth, etc.), and the 19 workers have different qualifications and ranks, which means that not all workers can operate all machines. At any point in time there may be a large number of orders processed on the floor simultaneously, thus rendering the production scheduling process (of deciding when and where to send each partially processed batch during the production cycle) a nontrivial task. The aim of the factory management is to be able to process orders within a time span of 15 workdays. However, as a result of a number of bottlenecks experienced during busy production runs, the factory staff is forced to work a substantial amount of overtime in order to meet their deadlines. The complexity of the job shop scheduling process (even for experienced floor managers) suggests that even a small improvement in the scheduling quality may alleviate bottlenecks experienced and hence reduce required overtime substantially. Again, two of the course lecturers were involved in MSc modelling projects on the Loubser Wood Components job shop scheduling problem during 2002, as project supervisors. Since this project formed part of only the 2002 course cycle, the lecturers (and especially their masters students) were in a position to deal with course students' questions during and after the site visit, by drawing on their problem experience and data gathered the previous year.

\section{A.4.2 The site visit}

The job shop scheduling problem at Loubser Wood Components was scaled down somewhat for the students by splitting up the actual factory into two smaller subfactories. A simplified version of the problem was then tackled by the two student groups, each group considering a different subfactory. For this reason it was decided to conduct a virtual tour with the students, instead of taking them to the factory and confusing the imaginary smaller subfactory problems with the original, real problem. The virtual visit was conducted by means of PowerPoint presentations by the two masters students involved, lasted in the region of one and a half hours and included virtual production floor tours, explaining with the aid of photographs, each stage in the production process in detail. Students frequently interrupted the tour with numerous questions on production 
scheduling policy, technicalities about wood processing, company finances, etc. During the course of the visit the masters students summarised in a vague (nearly dismissive) manner to the class what they perceived the objectives of the project to be: namely, to simulate (via computer) the production process, using stochastic order arrival times and quantities (derived from historical order data) with a view to identifing expected bottlenecks. Furthermore, based on the expected severity of these bottlenecks, the company was reportedly interested in the potential benefit of additional investment in infrastructure so as to reduce bottlenecks and hence overtime. Detailed production duration, machine capacity and demand data were supplied to the students in the form of tables at the end of the virtual tours.

\section{A.4.3 Theoretical background}

The site visit was preceded by a number of lectures on basic job shop scheduling techniques and discrete event driven computer simulation. Topics considered included a combination of graph theoretic scheduling techniques (such as the conjunctive-disjunctive graph method) and computer simulatuion techniques (using the software package Arena).

\section{A.4.4 Outcomes and success rating of the project}

In retrospect this was not a very successful course project. The problem lay not so much in the nature of the problem, but rather in how it was scaled down into two smaller subfactory job shop scheduling problems. What the lecturers did not foresee was that in one subfactory these simplifications caused a cessation of bottlenecks. Although the student group considering this particular subfactory could therefore not reduce bottlenecks, they still came up with a way to determine more realistic makespans for that part of the factory, thus changing the original objective of the project. We learnt that the scaling down of projects is a dangerous and tricky business, easily trivialising the problem. 